\title{
BMJ Open Young adults' perspectives on living with kidney failure: a systematic review and thematic synthesis of qualitative studies
}

\author{
Phillippa K Bailey, ${ }^{1,2,3}$ Alexander J Hamilton, ${ }^{1,4}$ Rhian L Clissold, ${ }^{5}$ Carol D Inward, ${ }^{6}$ \\ Fergus J Caskey, ${ }^{1,3,4}$ Yoav Ben-Shlomo, ${ }^{1}$ Amanda Owen-Smith ${ }^{1}$
}

To cite: Bailey PK, Hamilton AJ, Clissold RL, et al. Young adults' perspectives on living with kidney failure: a systematic review and thematic synthesis of qualitative studies. BMJ Open 2018;8:e019926. doi:10.1136/ bmjopen-2017-019926

- Prepublication history and additional material for this paper are available online. To view these files, please visit the journal online (http://dx.doi. org/10.1136/bmjopen-2017019926).

Received 3 October 2017 Revised 24 November 2017 Accepted 8 December 2017

\section{(1) CrossMark}

${ }^{1}$ Population Health Sciences, Bristol Medical School, Bristol, UK

${ }^{2}$ Translational Health Sciences, Bristol Medical School, Bristol, UK

${ }^{3}$ The Richard Bright Renal Unit, Southmead Hospital, North Bristol NHS Trust, Bristol, UK ${ }^{4}$ UK Renal Registry, Southmead Hospital, Bristol, UK

${ }^{5}$ Institute of Biomedical and Clinical Science, University of Exeter Medical School, Exeter, UK

${ }^{6}$ Paediatric Nephrology Department, Bristol Royal Hospital for Children, Bristol, UK

Correspondence to Dr Phillippa K Bailey; pippa.bailey@bristol.ac.uk

\section{ABSTRACT}

Introduction Young adults fare worse than younger adolescents or older adults on a broad range of health indicators. Those with a chronic illness such as renal failure are a particularly vulnerable group, who experience poor outcomes compared with both children and older adults. Understanding how being in receipt of renal replacement therapy (RRT) affects the lives of young adults might help us to better prepare and support these individuals for and on RRT, and improve outcomes. This study aimed to synthesise research describing young adults' experiences of the psychosocial impact of kidney failure and RRT.

Design A systematic literature review identified qualitative research reporting the perspectives of people aged 1630 years receiving RRT on the psychosocial impact of renal failure. Electronic databases (including Medline/EMBASE/ PsycINF0/ASSIA) were searched to November 2017 for full-text papers. The transparency of reporting of each study was assessed using the Consolidated Criteria for Reporting Qualitative Health Research (COREQ) framework. Quality was assessed using the Critical Appraisal Skills Programme qualitative checklist. An inductive thematic synthesis was undertaken.

Participants Seven studies from five different countries were included, comprising 123 young adults receiving RRT.

Results Comprehensiveness of reporting was variable: studies reported 9-22 of the 32 COREQ-checklist items. Three global themes about the impact of kidney failure on young adults were identified: (1) difference desiring normality, (2) thwarted or moderated dreams and ambitions, and (3) uncertainty and liminality. These reflected five organising themes: (1) physical appearance and body image, (2) activity and participation, (3) educational disruption and underachievement, (4) career ambitions and employment difficulties, and (5) social isolation and intimate relationships.

Conclusions Across different countries and different healthcare settings, young adults on RRT experience difference and liminality, even after transplantation. Tailored social and psychological support is required to allow young adults to experience wellness while in receipt of RRT, and not have life on hold.
Strengths and limitations of this study

- This is the first attempt to synthesise the existing qualitative literature that investigates the impact of renal failure on young adults.

- The number of participants included was large and multinational.

- The emergent themes were represented across the included studies, supporting the validity of the findings.

- The quality of reporting of the included studies was variable, and the quality of the research undertaken was sometimes difficult to assess due to the poor standard of reporting.

\section{INTRODUCTION}

Young adults fare worse than younger adolescents or older adults on a broad range of health indicators. ${ }^{1-3}$ Those with a chronic illness such as renal failure are a particularly vulnerable group. ${ }^{4}$ Most young adults on renal replacement therapy (RRT) have a kidney transplant: in the UK $73 \%$ of people aged 18-24years on RRT have a functioning transplant. ${ }^{5}$ Young adults with a transplant have an increased risk of transplant graft failure compared with both children and older adults. ${ }^{6}$ Understanding how renal failure affects the mental health, education, career ambitions, social lives and relationships of young adults might help us to better prepare and support these individuals for and on RRT, and improve outcomes.

Qualitative research can provide valuable insight into the impact of disease on an individual's life and lived experience, but single qualitative studies are often from one geographical area or healthcare centre, and often focus on a single aspect of experience rather than a spectrum. Thematic syntheses combine the findings from individual studies, to generate a rich, holistic, more complete 
understanding of the phenomena being investigated ${ }^{8}$ and generate new findings.

This thematic synthesis aimed to identify and synthesise qualitative research describing how kidney failure impacts on the lives of young adults, to identify areas which might require research and clinical attention, to ultimately improve patient outcomes. A systematic review and meta-analysis of the quantitative research on the psychosocial impact of RRT on young adults was undertaken alongside this qualitative synthesis, the results of which are reported elsewhere. ${ }^{9}$ This paper presents the findings of the qualitative literature synthesis, which might help us to explain the quantitative findings, adding the patient voice and rich context to numerical results. ${ }^{10}$

\section{METHODS}

We followed the Enhancing Transparency in Reporting the Synthesis of Qualitative Research framework. ${ }^{11}$

\section{Search strategy}

A sensitive search strategy was applied to nine databases (Medline, EMBASE, PsycINFO, ASSIA, CINAHL, Web of Science, Scopus, Open Grey and Cochrane Library). The full search strategy for the Medline, EMBASE and PsycINFO databases is provided as online supplementary material. We ran our first search in July 2015, and a final search in November 2017, for the latter limiting results to those from the last year only. We used EndNote to identify duplicate studies. AH screened the titles and abstracts of all the citations resulting from the search to identify studies fulfilling the inclusion criteria. PB screened the titles and abstracts of all the citations resulting from the final search. RC screened a random sample of 1000 titles and abstracts to ensure consistency. Any disagreements were resolved by discussion. When the literature database did not already provide a translated title and abstract, Google Translate was used to screen non-English abstracts: no relevant non-English articles were identified.

\section{Study selection}

We included qualitative studies of young adults (aged 16-30 years) on RRT (dialysis and transplants) that explored participants' perspectives on and experiences of the impact of renal failure on their lives (including education, employment, social life, relationships and psychological health). Studies were included if all or the majority $(>50 \%)$ of participants were in this range. When studies included participants aged $<16$ or $>30$ years, quotes from those participants were excluded from analysis. There is no consensus definition for young adulthood, and we chose a priori a wider age range to ensure that we did not miss any important publications. Globally, the legal age at which individuals enter adulthood varies between 16 and 21, and there is generally a gradual transition to full adult status. All included qualitative articles were double-checked by PB to ensure they met the inclusion criteria. The references of identified articles were screened to identify any additional papers. One study ${ }^{12}$ analysed interviews with young people who had chronic kidney disease as well as individuals on dialysis. The lead author was contacted to request access to the original transcripts of those patients on dialysis, but the study's ethical approval did not allow transcripts to be shared. A decision was made to include this study, extracting the findings but excluding the quotes from individuals not on RRT. This decision was made as the paper was the highest quality study identified, the majority of the illustrative quotes were from individuals on dialysis (30/39 quotes presented in table), and the themes identified were deemed relevant to our study, and overlapped with findings from other included studies.

We assessed the transparency of reporting of each study using the Consolidated Criteria for Reporting Qualitative Health Research (COREQ) framework. ${ }^{13}$ The quality of the included studies was assessed using the Critical Appraisal Skills Programme Qualitative Research Checklist. ${ }^{14} \mathrm{~PB}$ assessed all seven studies. $\mathrm{RC}$ and $\mathrm{AH}$ independently assessed two papers and any differences were discussed as a group. No study with relevant data was excluded from the synthesis.

\section{Thematic synthesis}

Inductive thematic synthesis was undertaken with reference to the method outlined by Thomas and Harden. ${ }^{15}$ The text in the results sections of each article was extracted electronically and entered verbatim into NVivo V.10 qualitative software ${ }^{16}$ for analysis. Data were analysed inductively. Line-by-line coding was undertaken, assigning sections of text descriptive labels. Codes were then grouped on the basis of shared properties to create concepts, which were grouped into themes. Subsequent studies were coded into pre-existing concepts, and new concepts were created when deemed necessary. Thus, themes were identified and analytic induction used to identify any patterns arising. Relationships between themes were identified and explored. $\mathrm{PB}$ and AOS independently coded all the papers. PB and AOS discussed their findings and any coding discrepancies to maximise rigour and reliability.

\section{RESULTS}

We included seven studies (figure 1), from five different countries, comprising 123 young adults receiving RRT. All studies were published in English; two were undertaken in countries in which English was not the primary language. All studies used in-depth semistructured interviews to collect data, with some also using focus groups, diaries and questionnaires (table 1).

Comprehensiveness of reporting was variable: studies reported between 9 and 22 of the 32 COREQ-checklist items (table 2). Only four studies reported that theoretical data saturation had been reached. One study reported that this had been reached after only interviewing five participants ${ }^{17}$ which is unexpected with such a small 


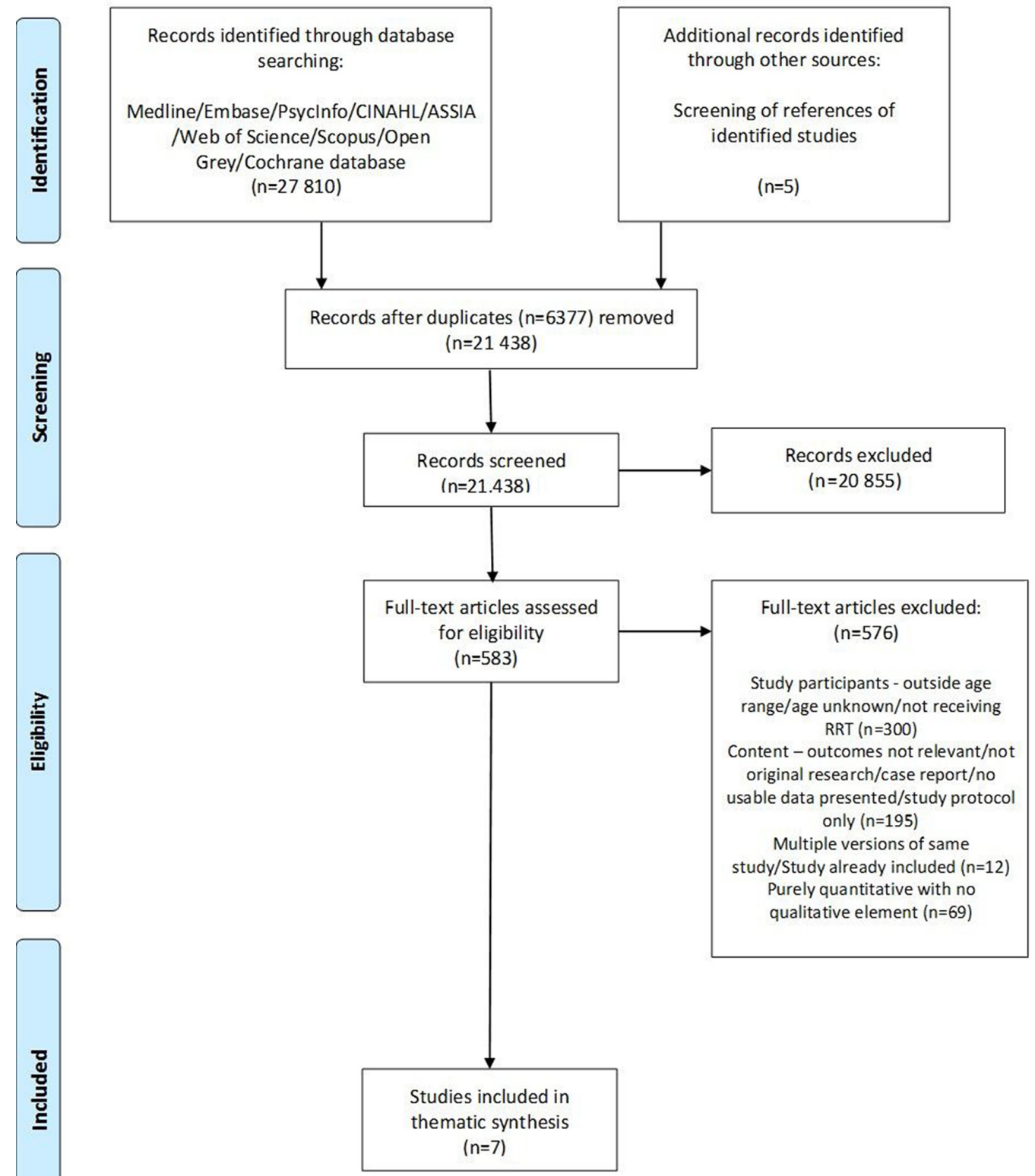

Figure 1 Systematic search results for studies. RRT, renal replacement therapy.

sample. Only one study was accompanied by an interview topic guide. ${ }^{12}$ One paper presented the findings from a mixed-methods study, but details regarding the qualitative analysis were lacking. ${ }^{18}$ Two studies suggested differences in the experiences of young adults who developed renal failure as children compared with those who were diagnosed as young adults. ${ }^{12} 19$ The quality of the studies was sometimes difficult to assess due to poor reporting: findings are presented in table 3 .

\section{Themes}

Three global themes about the psychosocial impact of renal failure on young adults were identified: (1) difference desiring normality, (2) thwarted or moderated dreams and ambitions, and (3) uncertainty and liminality. These reflected five organising themes: (1) physical appearance and body image, (2) activity and participation, (3) educational disruption and underachievement, (4) career ambitions and employment difficulties, and (5) social isolation and intimate relationships (figure 2).

Results are now presented under the three global themes with reference to the organising themes. Participant quotes illustrate themes. When reported in the primary research paper the characteristics of the person to whom the quote belongs are provided after the quote: Key: Age (in years), Sex ( $\mathrm{M}=$ male; $\mathrm{F}=$ female), RRT ( $\mathrm{HD}=$ haemodialysis; $\mathrm{PD}=$ peritoneal dialysis; $\mathrm{Tx}=$ transplant $)$.

\section{Difference desiring normality}

Study participants reported that they felt different to their peers; difference appeared to be perceived and reported as negative by all participants, who expressed 


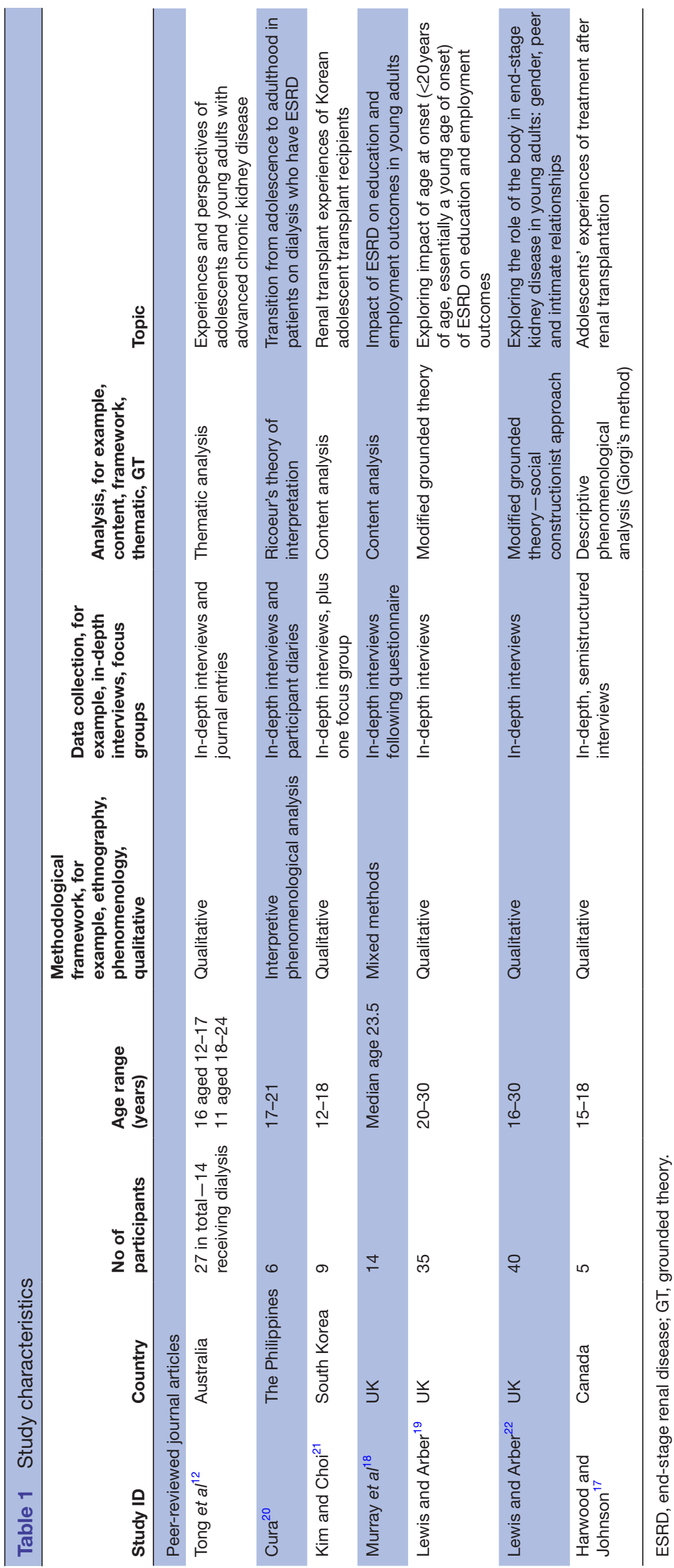

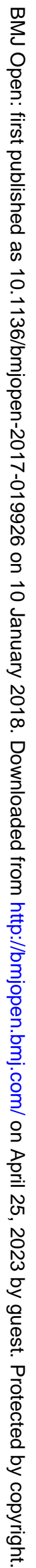


Table 2 Comprehensiveness of reporting

\begin{tabular}{|c|c|c|c|c|c|c|c|c|}
\hline \multirow[b]{2}{*}{ COREQ item $^{13}$} & \multicolumn{7}{|c|}{ Study reference } & \multirow[b]{2}{*}{$\begin{array}{l}\text { No of } \\
\text { studies }\end{array}$} \\
\hline & $\begin{array}{l}\text { Tong } \\
\text { et } \mathrm{al}^{12}\end{array}$ & $\begin{array}{l}\text { Harwood and } \\
\text { Johnson }^{17}\end{array}$ & $\begin{array}{l}\text { Murray } \\
\text { et } a^{18}\end{array}$ & $\begin{array}{l}\text { Lewis and } \\
\text { Arber }^{19}\end{array}$ & $\begin{array}{l}\text { Lewis and } \\
\text { Arber }^{22}\end{array}$ & Cura $^{20}$ & $\begin{array}{l}\text { Kim and } \\
\text { Choi }^{21}\end{array}$ & \\
\hline \multicolumn{9}{|l|}{ Domain 1: research team and reflexivity } \\
\hline Researcher credentials & $x$ & & & $x$ & & $x$ & & 3 \\
\hline Occupation of researcher & & & & & & $\mathrm{x}$ & & 1 \\
\hline Experience and training & & & & $x$ & & & & 1 \\
\hline $\begin{array}{l}\text { Prior/existing relationship with } \\
\text { participants }\end{array}$ & & & & & & & & 0 \\
\hline Participant knowledge of interviewer & & & & & & & & 0 \\
\hline $\begin{array}{l}\text { Interviewer characteristics, for } \\
\text { example, bias, assumptions, interest } \\
\text { in topic }\end{array}$ & & & & $x$ & & & & 1 \\
\hline Sampling strategy & $x$ & $x$ & $x$ & $x$ & $x$ & $x$ & $x$ & 7 \\
\hline Method of approach/invitation & $x$ & $x$ & & & & & & 2 \\
\hline Sample size & $\mathrm{x}$ & $\mathrm{x}$ & $\mathrm{x}$ & $\mathrm{x}$ & $\mathrm{x}$ & $\mathrm{x}$ & $\mathrm{x}$ & 7 \\
\hline Non-participation & $x$ & & & & & & & 1 \\
\hline Setting of data collection & $x$ & & & $x$ & $\mathrm{x}$ & $x$ & $x$ & 5 \\
\hline Presence of non-participants & $x$ & & & & & & $x$ & 2 \\
\hline $\begin{array}{l}\text { Description of sample, for example, } \\
\text { demographics }\end{array}$ & $\mathrm{x}$ & $x$ & & $\mathrm{x}$ & $\mathrm{x}$ & $x$ & $\mathrm{x}$ & 6 \\
\hline Interview guide & $x$ & & & & & & & 1 \\
\hline Repeat interviews & & & & & & $x$ & & 1 \\
\hline Description of coding tree & & & & & & & & 0 \\
\hline $\begin{array}{l}\text { Derivation of themes - in advance or } \\
\text { derived }\end{array}$ & $x$ & $x$ & $x$ & $x$ & $x$ & $x$ & $x$ & 7 \\
\hline Software & $x$ & & $x$ & $x$ & $x$ & & & 4 \\
\hline Participant checking & & & & & & & $x$ & 1 \\
\hline Quotations presented & $x$ & $x$ & $\mathrm{x}$ & $x$ & $x$ & $x$ & $\mathrm{x}$ & 7 \\
\hline Data and findings consistent & $x$ & $x$ & $\begin{array}{l}\text { X } \\
\text { But primarily quantitative } \\
\text { analysis - qualitative } \\
\text { themes under-reported }\end{array}$ & $x$ & $x$ & $x$ & $x$ & 7 \\
\hline Clarity of major themes & $x$ & $x$ & & & $x$ & $x$ & $x$ & 5 \\
\hline Clarity of minor themes & $x$ & $x$ & & & & & & 1 \\
\hline Total no of COREQ items & 22 & 12 & 9 & 16 & 13 & 18 & 15 & \\
\hline
\end{tabular}

COREQ, Consolidated Criteria for Reporting Qualitative Health Research.

strong desires to be 'normal'. Difference was primarily characterised by differences in physical appearance, and by differences in ability to participate in activities. While young adults who had developed renal disease in childhood reported desiring a perceived normality, young adults who developed renal failure in young adulthood also described 'an unbearable loss' of a previously experienced normality. ${ }^{12}$

Going from living a normal life, from what I knew, to being in hospital most of the time...I don't like it. $(18, \mathrm{M}, \mathrm{HD})^{12}$ [Key: Age, Sex, RRT 


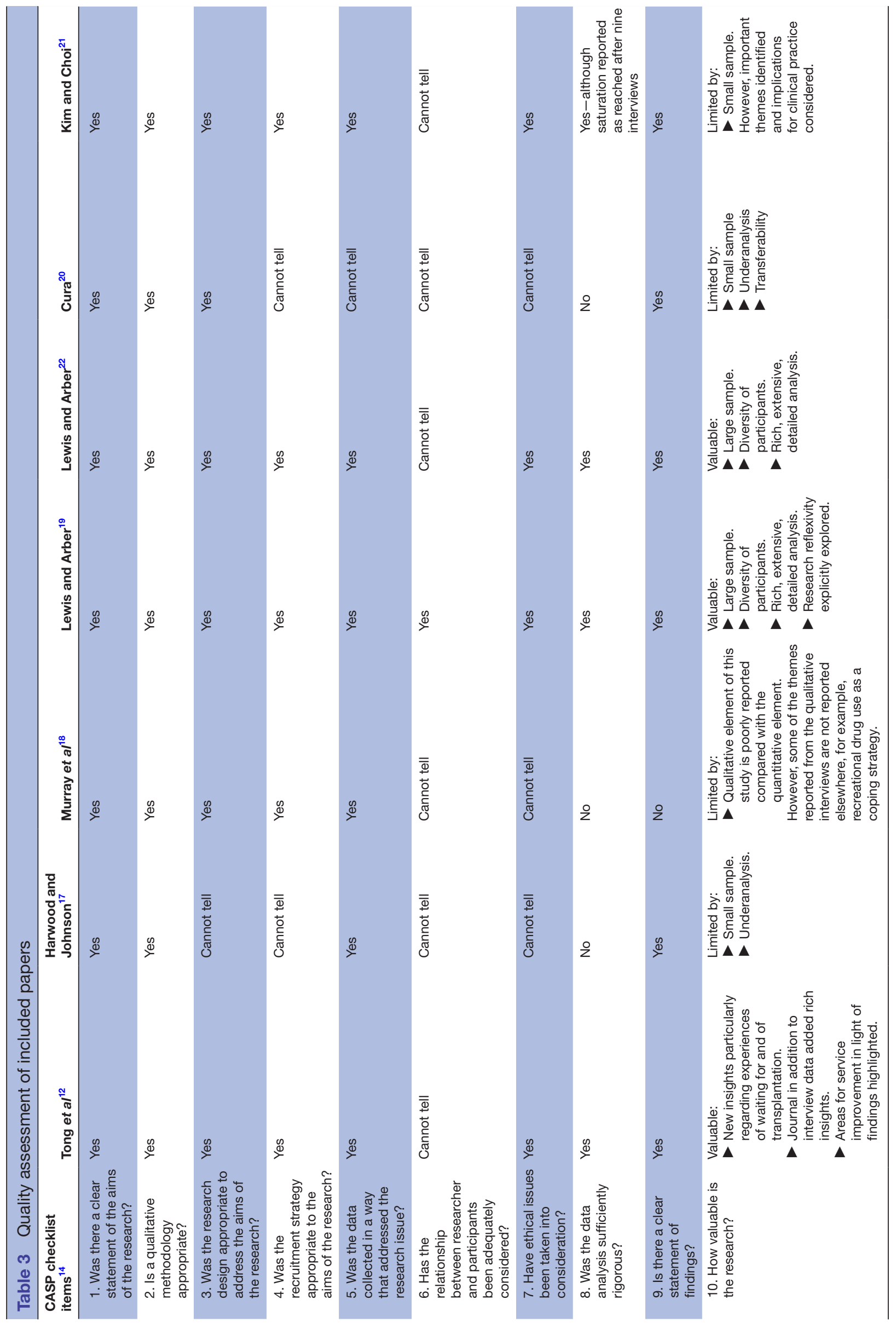




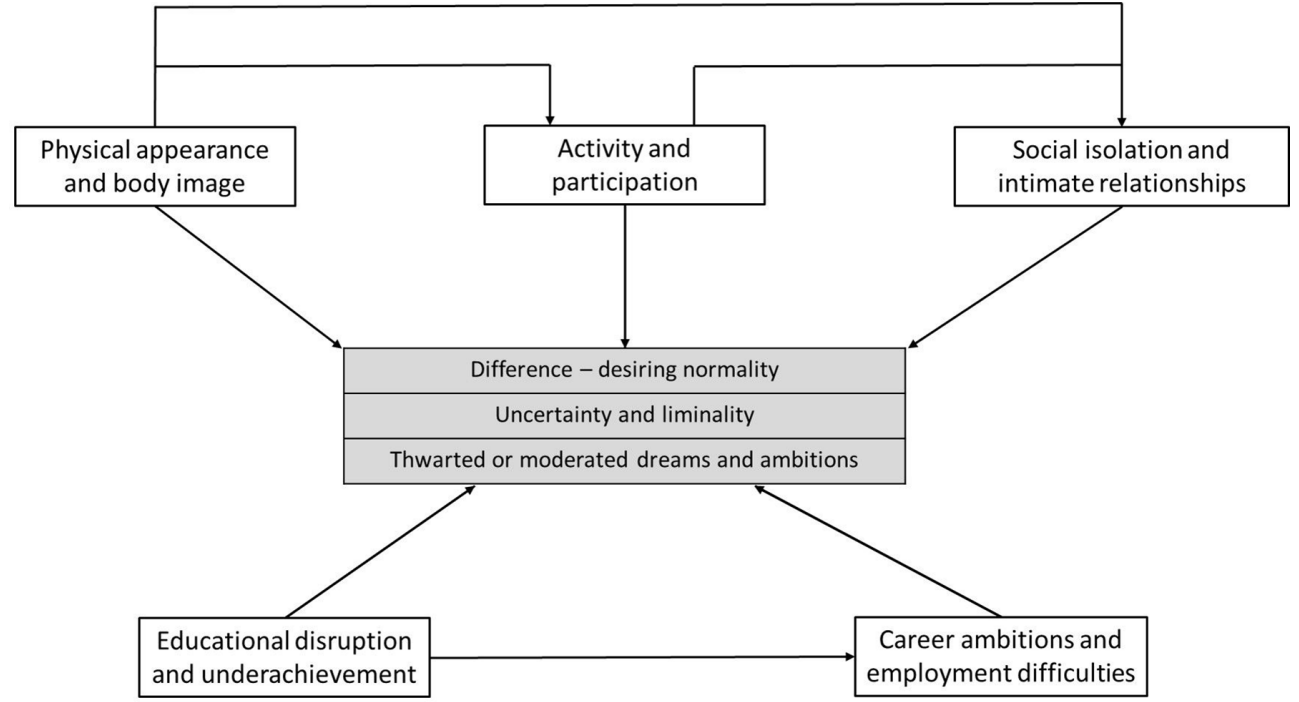

Figure 2 Thematic schema.

(HD=haemodialysis; Tx=transplant) ]

To look at me just like before, when I did not have the illness. Treat me normally. $(18, \mathrm{M}, \mathrm{HD})^{20}$

\section{Physical appearance and body image}

Participants across studies reported problems with being physically different to peers, due to surgical interventions (eg, peritoneal dialysis catheters), medication (eg, weight gain) and chronic illness (eg, short stature).

It can make you a bit like self-conscious if you have the tube. You worry that people can see it through your clothes or the scars... $(16, \mathrm{~F}, \mathrm{PD})^{12}$

These differences in physical appearance were often described using terminology suggesting a sense of dehumanisation and mechanisation, such as looking 'like a robot' and feeling like a 'wood block.' ${ }^{21}$

Many participants described finding that to some extent transplantation provided the physical normality they'd desired, resulting in:

\section{[a] face without swelling, and no more being hairy ${ }^{21}$}

However, others experienced further physical changes following transplantation:

I'm covered in scars... my face is really fat... I just hate looking at myself, I think I look like a freak. $(28, \mathrm{~F}, \mathrm{Tx})^{22}$

...prednisone [steroids] makes me eat a lot and gain weight... ${ }^{17}$

\section{Activity and participation}

As well as physical differences preventing individuals from feeling 'normal', study participants reported barriers to participating in everyday activities. Being able to participate in sport ${ }^{22}$ and education were seen as particularly vital to being normal:
While being on dialysis, I couldn't soak in water. When I went to a water park after the transplant, it was quite wonderful as I didn't need to attach a bandage to my body anymore, could get along with friends, and was not different from others. $(17, \mathrm{~F}, \mathrm{Tx})^{20}$

The local education... wanted me to go to a special school, for people with learning difficulties... My Mum and Dad were like, 'No, he hasn't got a physical disability, it's a medical condition, we want him to go to a normal school like all his friends and be treated normally. $(27, \mathrm{M}, \mathrm{HD})^{18}$

Young adults tried to engage in the same activities as their peers, by denying their health problems, lying about hospital appointments and missing medication when socialising:

I'd lie [about missing school for clinic]. I'd say I went to visit my girlfriend you know. You don't say 'I went to the hospital,' ...It's stupid. I just say I went to visit someone, or I didn't feel like coming. ${ }^{16}$

I didn't take (my tablets) on time, ever... It was an embarrassment... I was going out with friends, they were drinking, smoking, doing things and there was me with a tablet box. $(26, \mathrm{~F}, \mathrm{Tx})^{21}$

A few participants described feeling a sense of normality when they had individually accepted their health problems, and had successfully developed an identity separate to their illness:

[I started] to build more of an identity for myself that wasn't so centred on my illness and it was more like...I do have an illness yet I still want to establish that I'm a normal teenager like everyone else. $(19, \mathrm{M}, \mathrm{HD})^{12}$

\section{Thwarted or moderated dreams and ambitions}

Many participants described a sense of underachievement and lost opportunities, related to education, employment and intimate relationships. 


\section{Educational disruption and underachievement}

Young adults reported that renal failure negatively impacted on their educational achievement whatever their educational level when starting RRT:

Cos I'd started haemo... my [high school exam] results were really quite bad... I was really, really upset... I went on to University... but I'd still not done English and Maths. $(24, \mathrm{~F}, \mathrm{Tx})^{19}$

Some participants directly attributed educational underachievement to their disease and treatment, while others felt personally responsible, reporting that they had allowed their illness to affect their achievements:

When everyone was graduating year 12, I'm thinking oh, that could have been me if I didn't let everything get in the way. $(18, \mathrm{~F}, \mathrm{HD})^{12}$

Many participants, despite feeling they had underachieved, had often still succeeded in gaining significant qualifications:

For the whole of my Finals year I was on dialysis. It was quite a struggle, I would have got a 1st, but I got a $2(\mathrm{i}) \cdot(28, \mathrm{M}, \mathrm{HD})^{19}$

\section{Career ambitions and employment difficulties}

Participants moderated their career expectations with many reporting that they were able to find employment, but sometimes in jobs which were not what they'd hoped for:

I can get a job, like in a shop, but it doesn't really do much for me. $(29, \mathrm{M}, \mathrm{Tx})^{19}$

One participant powerfully described his gradual realisation of the impact of renal failure on his career ambitions $^{12}$ :

Interview quote: It's always been a military career for me and nothing else, and the thing is that this kidney puts that whole dream and that whole lifestyle at risk, like even if I get this [transplant], there's thousands of really strong men and nothing wrong with them at all that go for that and they don't get it, so you know like I have to work my arse off ten times harder and there's still no guarantee that I'm going to get it, and that's like the only career I've ever wanted, I can't think of myself doing anything else. I feel like that, this seems to have taken a lot of things away. $(16, \mathrm{M}, \mathrm{PD})^{12}$

Later journal entry: Today we went to hospital for some transplant education. It involved a detailed description of the procedure and medication I would go through. I was feeling good about it when a sudden realisation hit me. Since I would be on anti-rejection drugs to keep my immune system down so it would not attack the new kidney, I would be more likely to get disease and sick which makes a career in the army a not so likely future. I mean healthy normal men don't always get in and I'd be expected to fight in environments $\mathrm{w}[\mathrm{h}]$ ere disease like dysentery and malaria are common. As if the fact that I've had renal failure didn't screw up my chances enough. $(16, \mathrm{M}, \mathrm{PD})(\text { journal })^{12}$

Disclosure of their renal disease to employers was perceived, and had been experienced by some, as a challenge, the timing of which was thought to be crucial:

If you [kidney patient] put your CV in and you [employer] get a 'normal' CV in; 'I can work full time, there's nothing wrong with me.' Well, who would you choose? (Age not provided,F,Tx) ${ }^{17}$

My attitude... is to demonstrate... that I am more than capable of doing whatever it is that they want me to do. Once that has been established I tell them. I delay disclosure ... that is the tactic. $(28, \mathrm{M}, \mathrm{HD})^{18}$

\section{Social isolation and intimate relationships}

Participants described experiencing social isolation from peers as a result of their renal disease. Sometimes this was associated with self-imposed isolation due to a dislike of their physical appearance (see 'Physical appearance and body image'):

(Transplantation) made me...huge basically...I didn't go out for...about 3 months...'cos I felt like everyone was looking at me. $(19, \mathrm{~F}, \mathrm{Tx})^{22}$

Some participants reported experiencing namecalling ${ }^{17}$ and bullying by peers because of their physical difference. $^{21}$

Sometimes social isolation resulted from feeling physically unwell or due to needing to dialyse:

...you're so distanced from your friends, like they're off enjoying being eighteen, going to parties and everything, and I'm here stuck doing dialysis. $(18, \mathrm{~F}, \mathrm{HD})^{12}$

Renal failure was described by young adults as having a particularly significant impact on their confidence in pursuing, and ability to establish and maintain intimate relationships. Young adults were concerned with finding a partner who would accept their need for RRT:

With my future, I'm mostly worried about relationships. Will I ever meet a guy who'll be there for me no matter what? Will he care if I'm still doing dialysis? $(18, \mathrm{~F}, \mathrm{HD})^{12}$

Participants in several studies perceived rejection by a partner as being because of their renal disease. ${ }^{17} 22$ Some participants used the internet to find partners, and 'avoided the kind of pain incurred by more 'personal' rejection'. ${ }^{22}$

The themes of fertility and parenthood were key for older participants. There were multiple concerns, regarding fertility, heritable renal disease, the safety of pregnancy and the impact of renal disease on the ability to be a long-living and active parent: 
We'd love kids... But, do you pass the problem on... then die half-way through as well? $(27, \mathrm{M}, \mathrm{Tx})^{22}$

\section{Uncertainty and liminality}

The lives of the young adults appeared to be characterised by perpetual uncertainty. Participants across the studies expressed feelings suggestive of a sense of liminality related to their renal disease, that is, of experiencing periods of 'middle ground' or time spent 'treading water' before the final goal of receiving a transplant. During these liminal periods, participants described putting life 'on hold':

One participant 'cut his girlfriend off' while on dialysis. ${ }^{22}$ Others on dialysis decided to wait until they 'got a transplant' to seek a partner ${ }^{22}$ :

(I thought) I'm just going to... be on dialysis for a little while, have a transplant, then I can 'move on'

(find a partner), because everything's easier once you've had a transplant. $(28, \mathrm{M}, \mathrm{Tx})^{22}$

Participants described 'being shunted back and forth between wellness and illness, with intense periods of ill health, followed by variable periods of relative stability, sometimes lengthy, with a successful transplant. ${ }^{19}$ Young adults reported that periods of stability felt precarious and were often disrupted:

I had the dialysis problems at the wrong time...I'd just started (college) I thought I got them all sorted, then all re-occurred...so I had to stop the course. $(29, \mathrm{M}, \mathrm{Tx})^{19}$

For most participants, the liminal phase described time on dialysis before transplantation. However, the sense of finally having reached the 'end goal' of transplantation was often not sustained, as participants began to recognise that they were still different, and still had to manage restrictions in diet, medication and activities. ${ }^{21}$

Uncertainty was felt regarding all aspects of their lives, not just physical health, and included concerns regarding future employment, relationships and parenthood (see other organising themes).

\section{DISCUSSION}

Young adults reported that renal failure impacted on their ambitions and life goals, and their capacity and opportunities to achieve them. RRT impacted on their developing personal identity by affecting their education, career ambitions, employment capabilities, social activities and personal relationships. They described a sense of difference and uncertainty, both of which were intertwined with a sense of social isolation.

In qualitative syntheses of research with older adults, ${ }^{2324}$ participants have described RRT affecting their personal identity, as well as impacting on existing relationships with spouses/partners and children. ${ }^{23} 24$ This contrasts with our findings in young adults who describe renal failure as impacting on the development of their identity and their capacity to form relationships, and gain employment. The concerns of younger adults specifically relate to establishing key aspects of their lives, rather than managing the impact on an established life.

\section{Liminality}

The concept of liminality, developed by anthropologist van Gennep in his work on rites of passage,$^{25}$ describes a state of 'being inbetween' pre and post 'ritual' states. Turner described liminality as a space in which individuals are 'neither one thing nor another or maybe both', ${ }^{26}$ and a transitional intervening period between 'two relatively fixed or stable conditions'. ${ }^{26}$

The emerging adults in this study were already in a liminal state, between childhood and older/full adulthood. In addition, participants described being in a liminal state with respect to their renal disease, which in many ways prolonged the liminal phase they were already experiencing as a young adult as they put life 'on hold'. Liminality was particularly experienced on dialysis, while participants awaited transplantation. This has previously been described in the renal literature, ${ }^{27}{ }^{28}$ including the experience of transplantation not always delivering the desired/expected normality of wellness, and so in many ways continuing the liminal state. ${ }^{27}$

A recent quantitative systematic review and meta-analyses found that compared with healthy peers, young adults with transplants had lower quality of life. ${ }^{9}$ Our thematic synthesis suggested possible reasons for this, including the effects of transplant medications on appearance and ongoing restrictions in diet, medication and activities. The poor quality of life is also likely to be explained by the persistent sense of liminality, and experience of transplantation as not the 'normal life' that was anticipated pretransplantation.

This thematic synthesis found that young people had to moderate career expectations due to their disease, resulting in a mismatch between the jobs they wanted and those they were offered. Participants also reported difficulties disclosing their disease to employers, with a perceived impact on the likelihood of and security of employment. Many individual quantitative studies have reported that young adults on RRT are more likely to be unemployed ${ }^{18}{ }^{29-32}$; often despite education levels comparable to their healthy peers ${ }^{929} 32$, these qualitative findings highlight possible reasons for this.

Numerous quantitative studies have reported that young adults on RRT are less likely to be married or to have a long-term partner. ${ }^{9} 303334$ The thematic synthesis found that young adults reported that their renal disease had an impact on their confidence in pursuing, and ability to establish and maintain intimate relationships. Young adults reported concerns finding a partner who would accept their need for RRT, and many reported rejection as a result of their renal failure. Concerns regarding fertility, heritable disease and parenthood were also reported as impacting on relationships. The sense of difference identified in the synthesis is likely to both cause and result from the described differences in employment, intimate relationships and social isolation. 


\section{Clinical implications and future research}

Psychosocial outcomes in patients on RRT have been identified by older adult patients as a priority for future research. ${ }^{35}{ }^{36}$ At the moment, the research priorities of young adults are being investigated as part of the SONGKids priority setting work, which includes 'children aged up to 21 years' ${ }^{37}$ There is a need for specific research into the priorities of young adults.

Mental health appeared to have been underinvestigated in the included qualitative studies: two studies reported that two young adults had reported feeling suicidal $^{12}{ }^{17}$ but this was not described further. Some participants described feelings of hopelessness ${ }^{12}$ and body image concerns. Formal research into mental health problems in young adults with renal disease is required.

A number of clinical interventions could be considered to better support young adults on RRT, who have unique needs associated with the development of personal identity and achieving life aims. The development of young adult clinics (including individuals diagnosed in young adulthood as well as those transitioning from paediatric care) may allow support to be tailored to these needs. The inclusion of social workers, citizens advice volunteers, youth workers and psychologists in clinic, alongside CV-writing/interview skills workshops, and an area for socialising has been modelled in a UK centre. ${ }^{38}$ This model may be suitable for larger centres but a greater understanding is also needed of optimal models for smaller centres; providing this multidisciplinary support across conditions/disciplines for young adults with chronic illness could be considered.

Help with managing expectations of transplantation, and support to not put life 'on hold' while waiting is important. Young people need to be prepared for the reality of transplantation, which includes expectations of improved health, but with an ongoing treatment 'burden', possible complications and medication side effects. A mindfulness-based intervention has been reported as a possible way of helping people with chronic disease to 'experience wellness within illness' ${ }^{39}$

Social media, online resources and dating apps can support the development of social networks, especially for those with visible signs of RRT/body image issues who want to establish a relationship before meeting in person. Online communities have been found to be helpful in allowing young adults with cystic fibrosis to build an identity and sense of self, and have been shown to help develop a social community and sociability that extends beyond illness. ${ }^{40}$

\section{Strengths and limitations}

To our knowledge, this is the first attempt to synthesise the existing qualitative literature that investigates the impact of renal failure on young adults. The systematic review and synthesis were rigorous. While the number of included studies was small, highlighting young adults as an under-researched group, the number of participants included was large and multinational. The emergent themes were represented across the included studies, supporting the validity of the findings.

There were a few limitations: (1) the quality of the included studies was variable, and the quality of the research undertaken was sometimes difficult to assess due to the poor standard of reporting; (2) only one study published an interview topic guide, important themes may not have emerged due to limited questioning and (3) only two of the included studies explicitly reported the cultural or ethnic background of study participants ${ }^{12} 18$ and all studies were from high-income countries except for one. ${ }^{20}$ Findings may therefore not be transferable to individuals from ethnic minority groups or to different healthcare settings.

\section{CONCLUSIONS}

This thematic synthesis enhances our understanding of the experiences of young adults with renal failure. These results will help clinical teams to better support young adult patients and better address their holistic and complex needs. Findings will also help research teams focus on areas of particular importance to young adults.

Acknowledgements This work was presented as an oral presentation at the 18th Congress of the European Society for Organ Transplantation (ESOT) at Barcelona in September 2017. We would like to thank Penny Whiting for help in planning this review. We thank Dee Knipe, Mairead Murphy and Penny Whiting for their help with creating and managing a database for references. We acknowledge Catherine Borwick, specialist librarian, for assistance with the search strategy.

Contributors Research idea and study design: AJH, PKB, AO-S; data acquisition: AJH, RLC; assessment of reporting and quality: PKB, AJH, RLC; thematic synthesis: PKB, AO-S; data interpretation: PKB, AJH, RLC, FJC, YB-S, CDI, AO-S; supervision or mentorship: AO-S, YB-S, FJC, CDI. Each author contributed important intellectual content during manuscript drafting or revision and accepts accountability for the overall work by ensuring that questions pertaining to the accuracy or integrity of any portion of the work are appropriately investigated and resolved. PKB takes responsibility that this study has been reported honestly, accurately and transparently that no important aspects of the study have been omitted, and that any discrepancies from the study as planned (and if relevant, registered) have been explained.

Funding This study was funded by Kidney Research UK and Kidney Care UK. Competing interests None declared.

Provenance and peer review Not commissioned; externally peer reviewed. Data sharing statement № additional data are available.

Open Access This is an Open Access article distributed in accordance with the Creative Commons Attribution Non Commercial (CC BY-NC 4.0) license, which permits others to distribute, remix, adapt, build upon this work non-commercially, and license their derivative works on different terms, provided the original work is properly cited and the use is non-commercial. See: http://creativecommons.org/ licenses/by-nc/4.0/

(c) Article author(s) (or their employer(s) unless otherwise stated in the text of the article) 2018. All rights reserved. No commercial use is permitted unless otherwise expressly granted.

\section{REFERENCES}

1. Neinstein LS, Irwin CE. Young adults remain worse off than adolescents. J Adolesc Health 2013;53:559-61.

2. Park MJ, Paul Mulye T, Adams SH, et al. The health status of young adults in the United States. J Adolesc Health 2006;39:305-17.

3. Park MJ, Scott JT, Adams SH, et al. Adolescent and young adult health in the United States in the past decade: little improvement and 
young adults remain worse off than adolescents. $J$ Adolesc Health 2014:55:3-16.

4. Hamilton AJ, Casula A, Ben-Shlomo Y, et al. The clinical epidemiology of young adults starting renal replacement therapy in the UK: presentation, management and survival using 15 years of UK Renal Registry data. Nephrol Dial Transplant 2017;32:1434-5.

5. MacNeill SJ, Casula A, Shaw C, et al. UK renal registry 18th annual report: chapter 2 UK renal replacement therapy prevalence in 2014: national and centre-specific analyses. Nephron 2016;132(Suppl 1):41-68.

6. Foster BJ. Heightened graft failure risk during emerging adulthood and transition to adult care. Pediatr Nephrol 2015;30:567-76.

7. Van Arendonk KJ, James NT, Boyarsky BJ, et al. Age at graft loss after pediatric kidney transplantation: exploring the high-risk age window. Clin J Am Soc Nephrol 2013;8:1019-26.

8. Paterson B, et al. Meta-study of qualitative health research: a practical guide to meta-analysis and meta-synthesis. Thousand Oaks, CA: Sage Publications, 2001.

9. Hamilton AJ, Clissold RL, Inward CD, et al. Socio-demographic, psychological health and lifestyle Outcomes in young adults on renal replacement therapy. Clin J Am Soc Nephrol 2017;12:1951-61.

10. Tong A, Craig JC. Tuning into Qualitative Research-A Channel for the Patient Voice. Clin J Am Soc Nephrol 2016;11:1128-30.

11. Tong A, Flemming K, Mclnnes E, et al. Enhancing transparency in reporting the synthesis of qualitative research: ENTREQ. BMC Med Res Methodol 2012;12:181.

12. Tong A, Henning P, Wong G, et al. Experiences and perspectives of adolescents and young adults with advanced CKD. Am J Kidney Dis 2013;61:375-84.

13. Tong A, Sainsbury P, Craig J. Consolidated criteria for reporting qualitative research (COREQ): a 32-item checklist for interviews and focus groups. Int J Qual Health Care 2007;19:349-57.

14. Critical Appraisal Skills Programme (CASP). CASP qualitative research checklist. 2017 http://www.phru.nhs.uk/Doc_Links/ Qualitative\%20Appraisal\%20Tool.pdf (accessed 17 Nov 2017).

15. Thomas J, Harden A. Methods for the thematic synthesis of qualitative research in systematic reviews. BMC Med Res Methodol 2008;8:45.

16. NVivo qualitative data analysis Software. Version 10. QSR International Pty Ltd. 2012.

17. Harwood L, Johnson B. Weighing risks and taking chances: adolescents' experiences of the regimen after renal transplantation. Anna J 1999;26:17-21.

18. Murray PD, Dobbels F, Lonsdale DC, et al. Impact of end-stage kidney disease on academic achievement and employment in young adults: a mixed methods study. $J$ Adolesc Health 2014;55:505-12.

19. Lewis $\mathrm{H}$, Arber $\mathrm{S}$. Impact of age at onset for children with renal failure on education and employment transitions. Health 2015;19:67-85.

20. Cura J. Interpreting transition from adolescence to adulthood in patients on dialysis who have end-stage renal disease. J Ren Care 2012;38:118-23.

21. Kim S, Choi H. Experiences of Korean adolescent renal transplant recipients. J Spec Pediatr Nurs 2016;21:158-65.
22. Lewis $\mathrm{H}$, Arber $\mathrm{S}$. The role of the body in end-stage kidney disease in young adults: Gender, peer and intimate relationships. Chronic IIIn 2015;11:184-97.

23. Tong A, Lesmana B, Johnson DW, et al. The perspectives of adults living with peritoneal dialysis: thematic synthesis of qualitative studies. Am J Kidney Dis 2013;61:873-88.

24. Reid C, Seymour J, Jones C. A Thematic Synthesis of the Experiences of Adults Living with Hemodialysis. Clin J Am Soc Nephrol 2016;11:1206-18.

25. van Gennep A. Les rites de passage (in French). Paris: Émile Nourry, 1909.

26. Turner V. The forest of symbols: aspects of Ndembu ritual. Ithaca, NY: Cornell University Press, 1967.

27. Crowley-Matoka M. Desperately seeking "normal": the promise and perils of living with kidney transplantation. Soc Sci Med 2005;61:821-31.

28. Molzahn AE, Bruce A, Sheilds L. Learning from stories of people with chronic kidney disease. Nephrol Nurs J 2008;35:13-20.

29. Rocha S, Fonseca I, Silva N, et al. Impact of pediatric kidney transplantation on long-term professional and social outcomes. Transplant Proc 2011;43:120-4.

30. Mellerio $\mathrm{H}$, Alberti $\mathrm{C}$, Labèguerie $\mathrm{M}$, et al. Adult social and professional outcomes of pediatric renal transplant recipients. Transplantation 2014;97:196-205.

31. Lewis H, Marks SD. Differences between paediatric and adult presentation of ESKD in attainment of adult social goals. Pediatr Nephrol 2014;29:2379-85.

32. Aasebø W, Homb-Vesteraas NA, Hartmann A, et al. Life situation and quality of life in young adult kidney transplant recipients. Nephrol Dial Transplant 2009;24:304-8.

33. Reynolds JM, Morton MJ, Garralda ME, et al. Psychosocial adjustment of adult survivors of a paediatric dialysis and transplant programme. Arch Dis Child 1993;68:104-10.

34. Ehrich JH, Rizzoni G, Broyer M, et al. Rehabilitation of young adults during renal replacement therapy in Europe. 2. Schooling, employment, and social situation. Nephrol Dial Transplant 1992;7:579-86.

35. Urquhart-Secord R, Craig JC, Hemmelgarn B, et al. Patient and Caregiver Priorities for Outcomes in Hemodialysis: An International Nominal Group Technique Study. Am J Kidney Dis 2016;68:444-54.

36. Tong A, Sainsbury P, Carter SM, et al. Patients' priorities for health research: focus group study of patients with chronic kidney disease. Nephrol Dial Transplant 2008;23:3206-14.

37. Tong A, Samuel S, Zappitelli M, et al. Standardised Outcomes in Nephrology-Children and Adolescents (SONG-Kids): a protocol for establishing a core outcome set for children with chronic kidney disease. Trials 2016;17:401.

38. Chrysochou C. An innovative model for young adult renal care. BJRM 2016;21:60-3.

39. Doran NJ. Experiencing wellness within illness: exploring a mindfulness-based approach to chronic back pain. Qual Health Res 2014;24:749-60.

40. Allen C, et al. A meta-synthesis of qualitative papers. J Med Internet Res 2016;18:e61. 